\title{
The Derivation of Vocative Exclamatives with the Particle Paya in Gulf Arabic
}

\author{
Ghada Alkuwaihes ${ }^{1,2}$ \\ ${ }^{1}$ Department of Language \& Linguistic Science, University of York, York, United Kingdom \\ ${ }^{2}$ Department of English, Imam Abdulrahman Bin Faisal University, Dammam, Saudi Arabia
}

Email address:

gaaa500@york.ac.uk

\section{To cite this article:}

Ghada Alkuwaihes. The Derivation of Vocative Exclamatives with the Particle Paya in Gulf Arabic. International Journal of Language and Linguistics. Vol. 5, No. 5, 2017, pp. 121-126. doi: 10.11648/j.ij11.20170505.11

Received: July 10, 2017; Accepted: July 17, 2017; Published: August 2, 2017

\begin{abstract}
Research into vocative exclamatives (VocEs) is based on the traditional grammar of Standard Arabic (SA) which considers the structure of VocEs to be like that of vocatives due to the use of the vocative particle $y \bar{a}$. The problem with this traditional view lies in the fact that it only accounts for VocEs in terms of their similarity to vocatives, and identifies only one type of VocEs with the particle $y \bar{a}$ that exists in SA. However, other types of VocEs, their underlying structure and derivation have not been given much attention. Therefore, this paper examines the syntactic structure and the derivation of vocative exclamatives in Gulf Arabic with the particle ?aya which does not exist in SA. It provides an analysis of the data within the Minimalist Framework and sheds light on the main differences between their structure and that of vocatives in terms of definiteness and projection.
\end{abstract}

Keywords: Vocative Exclamatives, Exclamative Particles, Derivation of Exclamatives, Vocatives, Vocative Exclamative Particles, Gulf Arabic

\section{Introduction}

Exclamatives are a type of sentence that expresses surprise or feelings. Their structure has not been focused on as much as the structure of interrogatives and declaratives. Researchers, including [15] divided exclamative sentences into two main types based on their syntactic structure: exclamation and exclamative. The term exclamation is used to refer to utterances which express surprise in the form of a declaration. The term exclamatives refers to the utterances which express surprise in three different forms: Determiner Phrases (DPs), inversion and $w h$-questions.

Certain issues have been raised about the structural, semantic and pragmatic analysis of exclamatives. However, there is insufficient analysis of vocative exclamatives to the best of my knowledge. In Arabic, the studies on exclamatives have been concerned with Standard Arabic rather than the varieties of Arabic. Nowadays, Standard Arabic is no longer used as a spoken language. Rather, the colloquial Arabic is the spoken language which varies between the Arab countries according to their geographical regions [18]. Because of the wide range of Arabic dialects, there is insufficient syntactic data as it is the case with Standard Arabic. Moreover, the grammatical rules of the spoken dialects are continuously changing over time. Therefore, the rules of the grammar are not comprehensively documented [4].

Since Arabic dialects are not much studied, this research aims at investigating the syntactic structures and properties of vocative exclamatives with the particle ?aya in Gulf Arabic to enrich the linguistic data. This type of VocEs is worth investigation because it does not exist in SA, and therefore, it has not been tackled in the traditional grammar. The aim of this paper, then, is to examine their underlying structure and their derivation. This paper argues that vocative exclamatives with ?aya are derived from a $w h$-exclamative via ellipsis. It also proposes that Focus contributes to the derivation of vocative exclamatives and that the VocE particle ?aya licenses the ellipsis.

The structure of this paper is divided into four sections including this introduction. Section 2 mentions the previous studies related to vocatives, vocative exclamatives, particles and $w h$-exclamatives. Section 3 is dedicated for the syntactic analysis of vocative exclamatives with Paya in Gulf Arabic 
(GA) shedding light on the contrast between vocatives and vocative exclamatives. Finally, the paper ends with a conclusion in Section 4.

\section{Previous Studies}

\subsection{Vocatives}

Since the core of this research focuses on vocative exclamatives, it is important to mention the relation between vocatives and exclamatives pointing out the reason for labelling such type of exclamatives as vocative exclamatives. A vocative is a "form of direct address", as defined by [11]. Vocatives in SA have four main properties:

a) They include a vocative particle ${ }^{1}$.

b) The vocative particle acts as a pragmatic marker that selects a DP.

c) This particle has a second person $[2 p]$ feature.

d) The DP has a semantic value of animacy.

The following are two examples of vocatives in SA and GA:

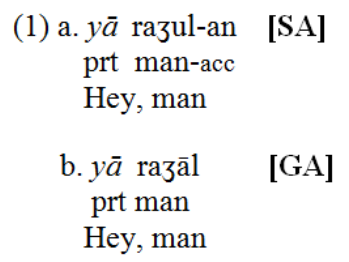

Besides the slight variation in the lexical word "man" in (1-a) and (1-b), the accusative case marker is overt in SA, while case is not phonologically realized in GA. The internal structure of vocatives in SA, according to the traditional grammar of Arabic and contemporary linguists including [10] and [17], covertly contains the verb ?u-nād call", This verb has been deleted after the insertion of the vocative particle $y \bar{a}$. What remains is the object which becomes the vocative noun (DP that occurs after the vocative particle). This assumption justifies the accusative case marker on the vocative noun. Therefore, the underlying structure of (1-a) would be the following:

\section{(2) Pu-nādī razul-an. [SA] I-call man-acc ${ }^{3}$ \\ I call a man.}

\subsection{Vocative Exclamatives}

The Arabic language has extended the use of the vocative particle to express an exclamative. A vocative exclamative, then, is a type of exclamatives that includes a vocative particle. In SA, the only vocative particle that is used in vocative exclamatives is $y \bar{a}$. In the traditional grammar of $\mathrm{SA}$, the structure of vocative exclamatives is considered as that of vocatives without a thorough analysis, [10] and [19].

\footnotetext{
${ }^{1}$ There are six vocative particles used in SA: yā, ?aya, haya, $\urcorner \bar{a}, ? a$ and $? a i$.

${ }^{2}$ pres $=$ present

${ }^{3}$ acc $=$ accusative case
}

(3) a. $y \bar{a}$ zamal-a al-hadīqat-a! prt beauty-acc the-garden-acc How beautiful the garden is!

b. $y \bar{a}$ hiluw al-hadīqah! prt beauty the-garden How beautiful the garden is!

[SA]

[GA]

The main differences between the properties of vocatives and vocative exclamatives can be summarized below:

1) The purpose of vocatives is a call or an address in which the addressee is present. In vocative exclamatives, however, the function of the particle is to mark an exclamative.

2) The vocative particle is only used to address animates, whereas the VocE particle can be used to exclaim about animate and inanimate.

Besides having the VocE particle $y \bar{a}$ in GA, another vocative particle is used for exclamatives which is ?aya.

(4) Paya al-hannan!

prt the-nagging

How nagging you are!

\subsection{Particles}

In the literature of Arabic language, the study of particles has been limited to the descriptive approach, focusing mainly on their grammatical function and case-marking system. It is until recently that researchers of Arabic have become interested in the syntactic properties of particles based on a Minimalist approach [1] and [2]. The syntactic properties of particles have become the interest of recent researches including [3], [13], [20] and [21].

\subsection{Wh-Exclamatives}

The most common type of exclamatives in Arabic as well as in English is the wh-exclamatives. They include a whoperator which has led to a comparative analysis between interrogatives and exclamatives. Some researchers considered exclamatives and interrogatives as distinct sentential types syntactically and semantically, such as [8], [14] and [24]. Others, including [5] and [7], argued that exclamatives are derived from interrogatives, and thus, they are similar.

As proposed by [8], the constructions of exclamatives and interrogatives are different for several reasons. First, interrogatives require subject-auxiliary inversion, yet exclamatives do not. In the following (5-b), he shows that inversion is ungrammatical in exclamatives.

(5) a. What lovely teeth you have, my dear! b. *What lovely teeth do you have, my dear! (p. 233)

Second, questions permit the negative polarity items (NPIs) any and ever, while exclamatives are ruled out if they include any of these NPIs.

(6) a. How does Joe save any money? b. *How Joe saves any money! 
Reference [8] concluded that exclamatives are not a type of interrogatives even though they share some similarities. This view has been supported by [14] who considered the similarity between these two constructions lies in the fact that both begin with a wh-word which moves to the specifier (spec) of a Complementizer Phrase (CP) position. However, exclamatives and interrogatives differ in their linear order, as exemplified in the following:

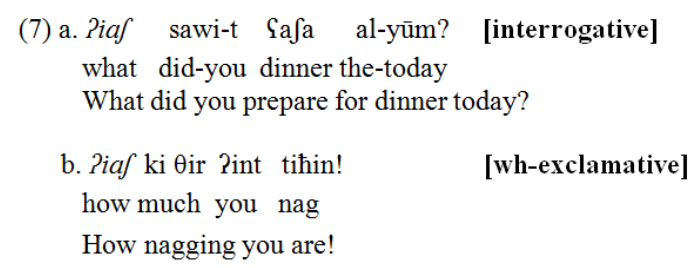

\section{Framework and Data Analysis}

The data of this research consists of vocative exclamatives with the particle ?aya from the Gulf Arabic dialect. These examples are commonly used in daily life conversations and are uttered frequently in TV series. The analysis is based on the minimalist framework following [6].

This type of vocative exclamatives is formed by the conjunction of the particle Paya and an adjectival phrase (AP). This particle functions as a vocative marker in SA which is only used for addressing a distant addressee. For this reason, the researcher considers this type of exclamatives as a vocative exclamative.

\section{(8) Paya muSalim-an! [Voc] \\ prt teacher-acc \\ Hey, teacher!}

The vocative in (8) exemplifies the following structure: Voc particle + indefinite DP. The Voc particle is associated with a [2-p] feature which justifies the absence of the prodrop you. It might be confusing having an accusative case marked on the vocative noun instead of a nominative case. The reason for this is traced back to the traditional grammar of SA which considers the underlying structure of vocatives to include the Verb Phrase (VP) ? $u-n \bar{a} d \bar{l}$ "pres-call” in which the overt DP is treated as the object of this underlying VP, [10] and [19]. In Gulf Arabic, this vocative particle ?aya is used as a vocative exclamative particle with a [2-p] feature.

\subsection{Syntactic Properties of Vocative Exclamatives with ?aya}

The following are examples of common vocative exclamatives found in Gulf Arabic:

$$
\begin{aligned}
& \text { (9) Paya al-sa } \overline{1} \mathrm{f}-\mathrm{ah} ! \\
& \text { prt the-silly-[fm] } \\
& \text { How silly you are! } \\
& \text { (10) Paya al-zarī?! } \\
& \text { prt the-bold[msc }{ }^{5} \\
& \text { How bold you are! }
\end{aligned}
$$

$$
\begin{aligned}
& \text { (11) Paya al-maznōn! } \\
& \text { prt the-crazy[msc] } \\
& \text { How crazy you are! } \\
& \text { (12) Paya al-hannan-ah! } \\
& \text { prt the-nagging-[fm] } \\
& \text { How nagging you are! }
\end{aligned}
$$

The above data indicates that vocative exclamatives with the particle ?aya have a specific structure and syntactic features. Concerning the structure, the VocE particle has a cselectional restriction in which the particle only selects a specific type of adjectives. This type of adjectives is called epithet adjectives. They describe a negative human personal trait, such as (greedy, lazy, stupid, nagging, etc.). Other types of adjectives do not fit in the construction of the vocative exclamative with ?aya.

$$
\begin{gathered}
\text { (13) a. * Paya al-qas }{ }^{2} \overline{\mathrm{r}} ! \\
\text { prt the-short[msc] } \\
\text { How short you are! } \\
\text { b. * Paya al-Pafgar! } \\
\text { prt the-blond[msc] } \\
\text { How blond you are! }
\end{gathered}
$$

An adjective which describes a positive human personal trait can be only used in a sarcastic way, so that its proposition would denote the opposite.

$$
\begin{aligned}
& \text { (14) Paya al-ðakī! } \\
& \text { prt the-smart[msc] } \\
& \text { How smart you are! }
\end{aligned}
$$

The interpretation of (14) conveys that the addressee is stupid rather than smart. To identify the structural features and the derivation of the vocative exclamatives with ?aya, I raise the following two questions:

1) Why does the adjective include a definite article? Can it be formed without this article?

2) What is the possible underlying structure from which VocEs are derived?

Unlike English, adjectives in SA, as well as the Gulf dialect, can have the definite article al-"the" 6 . The realization of a definite article appears to be obligatory in the structure of VocEs with ?aya because its absence would be considered ungrammatical.

$$
\begin{gathered}
\text { (15) a. * Paya saxif-ah! } \\
\text { prt silly-[fm] } \\
\text { How silly you are! } \\
\text { b. * Paya zarī?! } \\
\text { prt bold[msc] } \\
\text { How bold you are! } \\
\text { c. * Paya maznōn! } \\
\text { prt crazy[msc] } \\
\text { How crazy you are! } \\
\text { d. * Paya hannan-ah! } \\
\text { prt nagging-[fm] } \\
\text { How nagging you are! }
\end{gathered}
$$

\footnotetext{
${ }^{5} \mathrm{msc}=$ masculine

${ }^{6}$ Refer to [17] for more details.
} 
The researcher, hence, proposes that the VocE particle ?aya has an uninterpretable definite [D] feature that needs to be checked. Therefore, when forming the vocative exclamative, a definite article is merged with the adjective to form a definite phrase (DP). In line with [9], an adjective can be definite because of an agreement with the $\mathrm{D}$ feature when it is located under a DP.

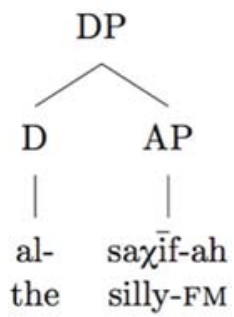

Figure 1. Tree representation of $D P$

The VocE particle ?aya is mainly associated with a [2-p] feature and with a [3-p] feature in some constructions. It has an uninterpretable [2-p] feature which is valued by the covert pronoun Pinta "you".

\subsection{Proposal}

The researcher proposes that vocative exclamatives with the particle ?aya are derived from a $w h$-exclamative whose structure can be represented as in the following tree:

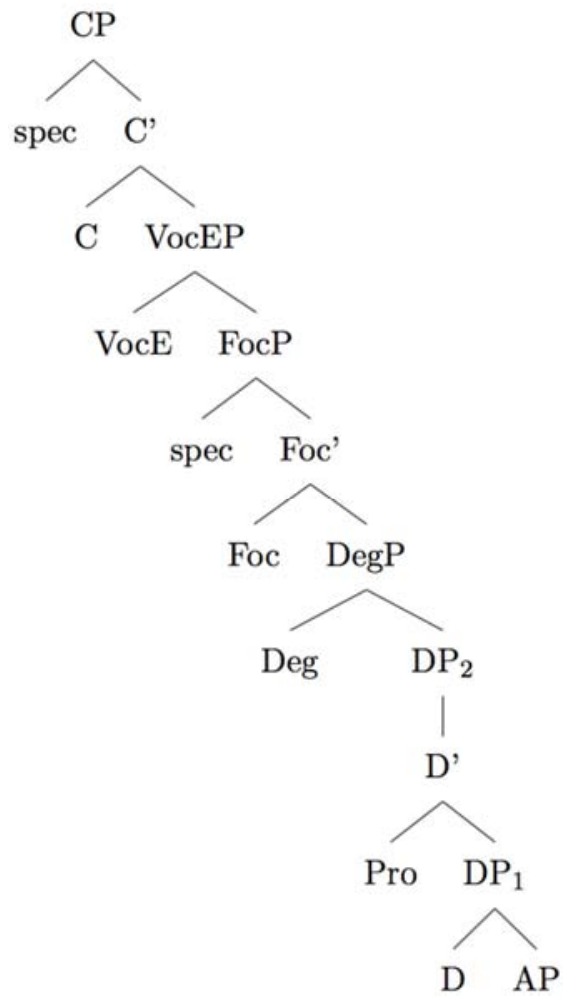

Figure 2. Tree representation of the derivation of VocEs.

Based on Figure 2, the following are two examples to present the derivation of the vocative exclamatives:

$$
\begin{aligned}
& \text { (16) a. Paya al-hannan! } \\
& \text { prt the-nagging } \\
& \text { How nagging you are! } \\
& \text { b. Pias ki } \text { ir Pint hannan! } \\
& \text { how much you nagging } \\
& \text { How nagging you are! }
\end{aligned}
$$

The vocative exclamative in (16-a) is derived from the whexclamative in (16-b).

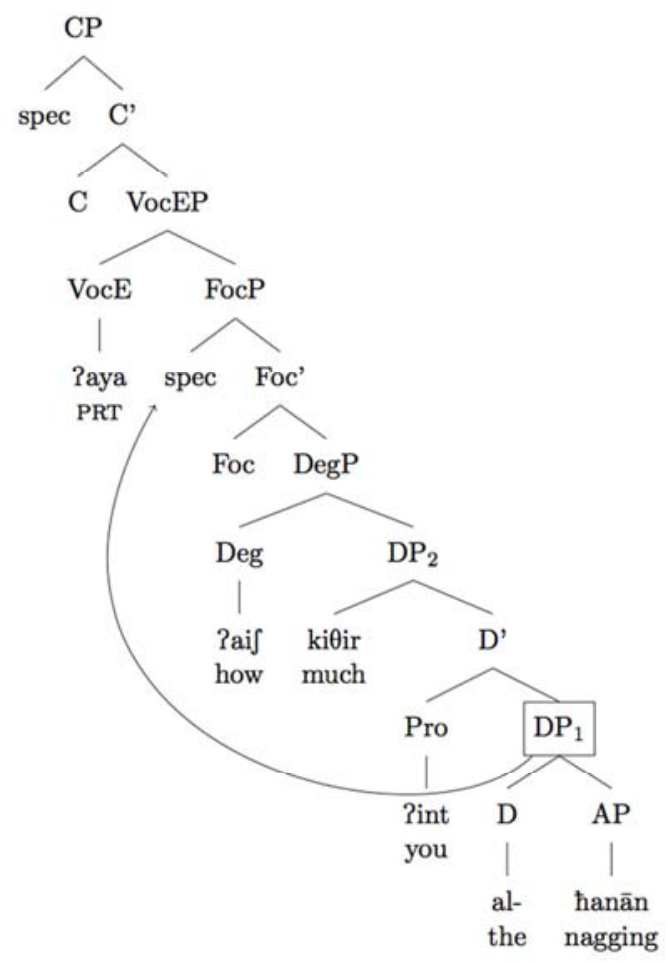

Figure 3. The derivational process of example (16).

The derivational process in Figure 3, as an example of a VocE with the particle ?aya, can be summarized as the following:

a) The adjectival phrase (AP) is merged with $\mathrm{D}$ to be checked for definiteness under the $\mathrm{DP}_{1}$ domain. However, agreement in gender and number does not exist between this particle and the adjective because it does not have gender or number restrictions.

b) A [2-p] feature is associated with the VocE particle. The presence of this particle, then, justifies the ellipsis of the pronoun Pinta" you". Arabic is a language characterized by covert pronouns, which justifies the ellipsis of the pronoun in VocEs.

c) Prior to the ellipsis of the Degree Phrase (DegP) and the lower elements, $\mathrm{DP}_{1}$ raises to the spec of Focus phrase (FocP).

d) The remnant elements after ellipsis is what create a vocative exclamative.

The analysis indicates that there is a relationship between Focus and ellipsis in VocEs. This relationship has been the interest of recent researchers including [16], [22] and [23]. 


\subsection{Vocatives Vs. Vocative Exclamatives with Paya}

An interesting comparison can be raised between the structure of vocative exclamatives with ?aya and vocatives with the ?aya particle which exists in SA to test whether they share a superficial similar structure or they are structurally distinct.

(17) Paya al- zaћūd! [VocE]

prt the-ungrateful[msc]

How ungrateful you are!

(18) Paya hakīm-an [Voc]

Hey wise[msc]-acc

Hey, wise

The superficial difference between the VocE in (17) and the Voc in (18) is related to definiteness and c-selection. Definiteness is obligatory in the VocE, whereas the latter disallows the definite article in its construction. The VocE particle selects an AP, while the Voc particle selects a nominal phrase. The other difference which leads to the conclusion that VocEs and Vocs should not be treated similarly can be related to the particle's position in the projection.

In vocatives, the Voc head position remains empty and the Voc particle occupies the spec of VocP position, as shown in Figure 4, [12].

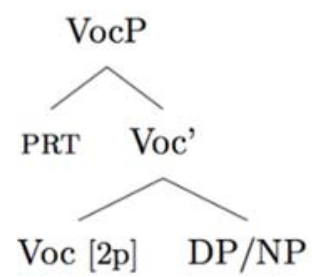

Figure 4. Tree representation of VocP.

Contrary to vocatives, the VocE particle in vocative exclamatives occupies the position of the head of the VocEP rather than its spec. FocP also appears in the structure of the vocative exclamative due to its necessity in hosting $\mathrm{DP}_{1}$ prior to the ellipsis operation of the pro.

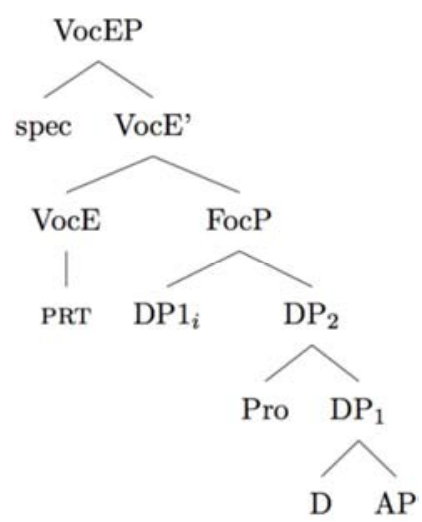

Figure 5. Tree representation of VocP.

\section{Conclusion}

Vocative exclamatives with the particle Paya in Gulf Arabic have a specific syntactic structure and properties which make them a distinct type of exclamatives. Their superficial structure is formed by the conjunction of this VocE particle with a definite epithet adjective, whereas it is derived from a $w h$-exclamatives in its underlying structure through ellipsis. For the ellipsis process to occur, $\mathrm{DP}_{1}$ should move first to the spec of FocP. Then, the DegP with its lower elements are then elided. The remnants of the ellipsis process create an overt VocE construction.

\section{Acknowledgements}

Special thanks and gratitude are dedicated to my supervisor George Tsoulas, Norman Yeo and Yolipo for their valuable comments and suggestions for this research.

\section{References}

[1] Alkuwaihes, G. (2016). Rethinking vocative and vocative exclamative particles in Arabic. Proceedings of LILA'16: International Linguistics and Language Studies Conference, pp. 241-248. DAKAM.

[2] Alshamari, M. (2017). The syntax of the clause-initial particle sedı in North Hail Arabic, in press. Poznan Studies in Contemporary Linguistics.

[3] Biberauer, T; Haegeman, L; and Kemenade, A. van, 2014. Putting our heads together: towards a syntax of particles. Studia Linguistica 68 (1), pp. 1-15.

[4] Brustad, K. (2000). The syntax of spoken Arabic: A comparative study of Moroccan, Egyptian, Syrian, and Kuwaiti dialects. Georgetown University Press.

[5] Chernilovskaya, A. (2010). Exclamatives have a question semantics! In Presentation at the 6th International Symposium of Cognition, Logic and Communication "Formal Semantics and Pragmatics: Discourse, Context, and Models", Riga, Latvia.

[6] Chomsky, N. (1995). The minimalist program, Volume 28. Cambridge University Press.

[7] d Avis, F. J. (2002). On the interpretation of wh-clauses in exclamative environments. Information Structure and the Referential Status of Linguistic Expressions (2001): 1.

[8] Elliott, D. E. (1974). Toward a grammar of exclamations. Foundations of Language, 231-246.

[9] Fehri, A. F. (1999). Arabic modifying adjectives and DP structures. Studia Linguistica 53(2), 105-154.

[10] Hassan, A. (2010). An-nahw Al-waffi" The Comprehensive Syntax" (17 ed.), Volume 3. Cairo: Dar Al-Ma'aref.

[11] Hill, V. (2007). Vocatives and the pragmatics-syntax interface. Lingua 117(12), 2077-2105.

[12] Hill, V. (2013). Vocatives: How syntax meets with pragmatics. Brill. 
[13] Jónsson, J. G. (2017). Discourse particles and hvaðexclamatives. In V. S. Josef Bayer (Ed.), Discourse Particles: Formal Approaches to Their Syntax and Semantics, pp. 100104. De Gruyter.

[14] Portner, P. and R. Zanuttini (2000). The force of negation in wh exclamatives and interrogatives. Negation and polarity: syntactic and semantic perspectives, 193-231.

[15] Rett, J. (2011). Exclamatives, degrees and speech acts. Linguistics and Philosophy 34(5), 411-442.

[16] Rooth, M. (1992). A theory of focus interpretation. Natural language semantics $1(1), 75-116$.

[17] Ryding, K. C. (2005). A reference grammar of modern standard Arabic. Cambridge University Press.

[18] Ryding, K. C. (2014). Arabic: A Linguistic Introduction. Cambridge University Press.
[19] Sibawayh, A. (1977). Al-Kitaab” The Book". Cairo, Dar AlQalam Press.

[20] Tsoulas, G; 2015. On the syntax and morpho pragmatics of particles: The case of Greek. University of York, unpublished.

[21] Tsoulas, G. and Alexiadou, A; 2006. On the grammar of the Greek particle $R e$ : A preliminary investigation. Sprache und Datenverarbeitung 30(1), pp. 47-56.

[22] Winkler, S. (2005). Ellipsis and focus in generative grammar, Volume 81. Walter de Gruyter.

[23] Winkler, S. and K. Schwabe (2003). Exploring the interfaces from the perspective of omitted structures. The interfaces: Deriving and interpreting omitted structures, 1-26.

[24] Zanuttini, R. and P. Portner (2003). Exclamative clauses: At the syntax-semantics interface. Language, 39-81. 